\title{
A Desire to Be Taught: Instructional Consequences of Intrinsic Motivation ${ }^{1}$
}

\author{
Mark R. Lepper ${ }^{2}$ and Diana I. Cordova \\ Stanford University
}

This paper summarizes the results from a series of studies designed to test the hypothesis that making learning more fun will produce corresponding increases both in learning and retention and in subsequent interest in the subject matter itself. Each study examined the effects of two or more versions of an educational activity, each designed to involve identical instructional content, but to differ in motivational appeal. The data from the studies presented provide good general support for the hypothesized cognitive and motivational benefits of appropriately designed motivational embellishments of educational activities. Exceptions to this rule, however, and a more general theoretical analysis of the conditions under which such positive effects are (and are not) expected to occur, are also discussed.

[When teaching a child] great care must be taken that it never be made a business to him, nor he look on it as a task. . .

I have always had a fancy that learning might be made a play and a recreation to children; and that they might be brought to a desire to be taught, if only learning were proposed to them as a thing of delight and recreation, and not a business or a task.

John Locke (1693)

In his Some Thoughts Concerning Education, published nearly three centuries ago, John Locke offered the foregoing hypothesis about the

${ }^{1}$ This research was supported, in part, by research grant HD-17371 from the National Institute of Child Health and Human Development to Mark R. Lepper.

${ }^{2}$ Address all correspondence, including requests for reprints, to Mark R. Lepper, Department of Psychology, Jordan Hall - Building 420, Stanford University, Stanford, California 94305-2130. 
relationship between interest and delight, on the one hand, and effective learning, on the other. Like other writers before and since, Locke began by noting the immense amount of seemingly "incidental" and untutored learning that occurs in young children and linked it to their seemingly incessant curiosity and their boundless delight in learning for its own sake. Like others before and after him, Locke also noted the contrast between this state and that of the child only a few years later, when learning seems often to have become a chore and so-called "motivational problems" seem first to develop.

For Locke, the causal arrow in this relationship was clear. What we learn, he argued, will depend on whether we see a particular opportunity for learning as a task and a business or as a thing of delight and recreation - whether we view that activity as "work" or as "play." Moreover, for Locke, there were clearly two sides to this relationship. On the one hand, he postulated that the imposition of salient extrinsic constraints which transform learning activities into tasks to be endured - turning play into work - might undermine subsequent learning. On the other hand, he hypothesized that the presentation of opportunities for learning in the form of play or recreation - turning work into play - might enhance learning. The former thesis has, as we shall see, already received considerable experimental support (e.g., Lepper, 1988); hence, it is the latter, less fully studied, thesis that we wish to consider in more detail in the present paper.

Two lines of existing research already provide some indirect support for this line of analysis. The first involves studies that have assessed the correlation between the rated interest value of written material and students' subsequent retention of that material. In studies by Anderson and his colleagues (Anderson, 1982; Anderson, Mason, \& Shirey, 1984; Anderson, Shirey, Wilson, \& Fielding, 1987), for example, an array of sentences is first rated for its interest value by members of a particular target group of students. Subsequently, other students from this same group are asked to study these sentences and are tested, at a later time, for their recall of the sentences. Using this procedure, Anderson and his colleagues have found a quite powerful correlation between the rated interest value of a sentence and the apparent ease with which it will be learned and retained.

In similar fashion, a number of studies by Asher and his associates (Asher, 1979, 1980; Asher, Hymel, \& Wigfield, 1978; Asher \& Markell, 1974) demonstrate comparable results with students seeking to learn the information imparted in more complex prose passages. Here again, the basic paradigm involves the assessment of the correlation between the rated interest value of a passage, as determined with one group of students, and 
the ease with which the material that passage contains is learned, as determined with a different group of students. Once again, the basic finding across these studies has been the observation of a high correlation between rated interest and ease of learning.

The second general line of research relevant to the present claims concerns the detrimental effects of tangible extrinsic rewards on student learning (e.g., Condry \& Chambers, 1978; McGraw, 1978). Many of these studies derive from a related literature showing that the imposition of a superfluous extrinsic reward on a student's engagement in an activity of high initial motivational appeal can often undermine that student's subsequent intrinsic interest in the task (e.g., Condry, 1977; Deci, 1975; Deci \& Ryan, 1985; Lepper, 1981, 1983; Lepper \& Greene, 1978). What once was play appears to become work - only when extrinsic rewards continue to be available will students now approach the activity; no longer will they freely choose to engage in the previously attractive activity for its own sake without some instrumental payoff.

Drawing on these initial studies of the detrimental effects of extrinsic rewards on intrinsic interest, subsequent experiments examined the possible deleterious effects of the offer of extrinsic rewards for successful task performance on students' learning and problem solving - on the assumption that decreased intrinsic motivation may have adverse effects on learning as well. In these experimental studies, students are typically asked to undertake a learning task, either with the expectation that their success at that task will lead to a tangible extrinsic reward or without the expectation of any such extrinsic reward. Given that the learning activity is both of initial interest to the student and of sufficient complexity that success cannot be achieved through any simple algorithmic procedure, the common result of the offer of a tangible extrinsic reward is to make learning more difficult (McGraw, 1978). Thus, students expecting an extrinsic reward have been shown to have more difficulty in "breaking set" (McGraw \& McCullers, 1979), more trouble in generating nonobvious solutions to complex "insight" problems (Glucksberg, 1962, 1964), more difficulty in generating artistic or literary products that are likely to be judged by outside experts as highly creative (Amabile, 1979, 1983), and the like.

Although supportive of our analysis, neither of these lines of investigation provides unequivocal support for the thesis of central interest here. On the one hand, the former literature, establishing a positive correlation between the interest value of passages and their retention in memory, does not necessarily establish the causal priority of interest value in learning. Perhaps the reverse is true, and students simply expressed a greater interest in passages that were more memorable; or perhaps differences in both 
learning and interest followed from some other factor, such as the distinctiveness of the contents of the passage.

On the other hand, the latter literature, demonstrating the detrimental effects of superfluous extrinsic rewards on intrinsic interest and learning, is similarly subject to potential alternative explanations. Perhaps, in these studies, differences in subsequent learning were mediated not by decreases in intrinsic interest, but by some other process. Perhaps learning suffered, for instance, because students became overly excited, or were simply distracted, by the prospect of obtaining exciting extrinsic rewards for learning.

\section{EMPIRICAL RESEARCH}

The more straightforward test of Locke's thesis, and the one that will provide the focus for the studies we wish to describe, would thus involve the experimental demonstration of the benefits for learning of making educational activities more intrinsically motivating for students. In these studies, therefore, we will be seeking to contrast the effects of exposure to different versions of a learning activity - versions of the activity carefully designed to present identical problems, feedback, instruction, and the like, but simultaneously to vary significantly in their motivational appeal to students. In each case, then, a basal learning activity will be contrasted with one or more motivationally embellished variants of that activity, in order to examine whether differences in motivational appeal (controlling for major cognitive variables) will produce corresponding increases in learning and retention, on the one hand, and enhanced subsequent interest in the subject matter itself, on the other.

In our initial studies along these lines, we should note, computerbased learning activities were used as the medium for our experimental investigations. There were two reasons for this choice. First, on methodological grounds, the computer seemed to provide a nearly perfect laboratory for the manufacture and study of learning activities that could be varied systematically along a single parameter of theoretical interest, while holding constant other aspects of instruction. Thus, in our studies, we could be certain that the different versions of our instructional activities would involve identical procedures for selecting problems for the student, for providing explicit preliminary instruction, for responding to correct or incorrect student answers, and the like. At the same time, use of the computer would also make it relatively easy for us to produce systematic variations of our activities along other dimensions. The graphics capabilities of the technology, in particular, allowed us to introduce additional gamelike elements into a variety of initially unembellished educational programs. 
The second reason for our choice was more societal: Computer-based learning happened to be a social context in which the use of strategies for presenting learning as play or recreation has been the subject of great controversy (Lepper, 1985). Because the technical capabilities of the computer made it so easy to make instructional drills into educational games, schools and teachers were often being offered very different alternative methods for accomplishing common curriculum goals. A proficiency in elementary arithmetic skills might be encouraged, for example, through the use of a straightforward "drill and practice" program that simply presented problems for solution and provided immediate corrective feedback to the student. Or, the same set of problems and accompanying feedback might be presented in the form of an electronic game in which each correct problem solution by the learner/player would blast a menacing alien spacecraft from the skies displayed on the computer screen. Even this simplest case, then, posed for parents and teachers a choice: From which of these programs would students in general, or this child in particular, benefit the most?

Opinion in the educational community was clearly divided. Proponents of computer-based educational games (e.g., Kleiman, 1984; Thornburg, 1981) sided with Locke. They believed that such activities, by enhancing student interest and involvement, would produce better learning and would lead to greater subsequent interest in the material being taught, even in the later absence of the game itself. Opponents (e.g., D'Attore, 1981; Psotka, 1982) saw the situation quite differently. For them, such games were seen as a cheap and misguided educational "fix" that was doomed to backfire in the end. By focusing students on educationally irrelevant features introduced in order to make a learning activity into a game, they argued, students will be distracted, and their attention diverted from learning the material. Not only will they learn less, however; in this skeptical view, these students were also predicted later to find the subject matter itself boring and uninviting, once the "bells and whistles" of the computer game were no longer present. Although children may enjoy the initial activity more when it is presented in the form of a game, they will come to detest study of the same material later, when it is presented in the traditional classroom context.

For these early studies, then, the computer provided both a vehicle for the design of controlled experimental variations in learning activities and a domain in which the use of instructional games and motivational embellishments was being actively debated. At the same time, the ubiquity and the vehemence of this debate suggested that there was not likely to be a universal answer to the questions we were posing about the potential value of such activities, but instead that 
there were probably both effective and ineffective forms of such activities. As a result, before undertaking our experimental studies, we spent a good deal of time simply observing the use of commercially available computer learning activities in local school systems and the effects they seemed to have on students.

These observations convinced us that the use of motivational embellishments in computer-based learning could sometimes have negative effects on learning (Lepper \& Malone, 1987; Malone \& Lepper, 1987). Clearly, a number of the activities we observed children using in schools at that time appeared to have purchased motivation at the expense of learning. These were activities that children found interesting and exciting, but from which they seemed to learn little, except how to "win" the game. The subject matter being presented seemed largely irrelevant.

In fact, the most general description of the central difficulty with these computer-based learning activities that seemed to excite, but not to educate, children was that they had been designed so that the goals of "learning the material" and "winning the game" were operating in conflict, rather than in concert. That is, for these activities, it proved possible for students to succeed in winning the game without learning, in the process, the material the game was designed to present. For instance, many programs had been inadvertently designed so that they permitted children to obtain winning scores by playing the game in a rapid, repetitive, mindless fashion that precluded learning of the material the program had been fashioned to present.

In our experimental studies to follow, therefore, we sought to ensure that the motivational and the educational goals of the activities we designed were mutually congruent, rather than at odds with one another, so that in all of our activities, success and enjoyment of the activity necessarily depended upon learning of the subject matter presented. Our concern, then, was whether the addition of such appropriately designed motivational embellishments to a learning activity - controlling for cognitive factors could produce corresponding increases, in learning from the activity and in subsequent interest in the subject matter itself, of the sort hypothesized three centuries earlier by Locke.

Our first study, therefore, involved the simplest possible test of these hypotheses, comparing two basic experimental conditions to a no-treatment control condition (Lepper \& Hodell, 1989). In both experimental conditions, selected third- through fifth-grade students were asked to spend three 30-min sessions working with either the relevant target program, a computer-based activity designed to teach students about the use of Cartesian coordinates, or a computer-based version of the traditional word 
game "Hangman." Students in the control group were given their choice of several educational programs, none of which dealt with Cartesian coordinates. In each session, each of the choices was continuously available to students, and students were encouraged to switch back and forth whenever they desired.

The two experimental conditions differed, of course, in the precise nature of the target program designed to teach students about Cartesian coordinates. In the basal, unembellished activity condition, following the initial instructional section, students were given the task of "finding" a "hidden dot" lying beneath one of the intersections of an $11 \times 11$ Cartesian grid displayed on the computer screen, with axes labeled from -5 to +5 . The student's task was to find the dot by guessing its location. After each incorrect guess, the student was provided with both written and visual feedback (in the form of an arrow pointing from the point guessed) concerning the general direction of the hidden point relative to the point guessed. After each correct guess, students were congratulated with feedback on the screen, and students were further praised by the program after each set of three correct answers.

In the embellished version of this program, this same activity and the same series of problems were presented within a fantasy context designed to heighten children's intrinsic interest in the program. Instead of merely hunting for hidden dots, the activity was presented as involving the student's helping a graphics character hunt for hidden treasures buried on a deserted island. In this version, when a correct guess was made, a small icon representing a "treasure" (e.g., an ivory comb, a silver goblet, or perhaps a rusty hook) appeared, accompanied by sound effects. After three correct answers, a screen showing the character rowing the three accumulated treasures to shore, was displayed. This second version, therefore, presented identical problems and provided identical corrective and evaluative feedback, but did so in the form of a game devised to make the activity more intrinsically motivating.

The motivational appeal of these two alternative versions of our target activity was measured by the amount of time during the sessions that the students chose to work with the target activity. The learning that occurred as a result of students' use of these programs was measured by

\footnotetext{
${ }^{3}$ These activities were developed from an original commercially available program, titled "Hidden Treasure," that was included in a package of educational computer games published by The Learning Company of Menlo Park, California. The modifications of its program needed for the design of our study were made on source code provided to us by The Learning Company and were done with its permission. We are greatly indebted to the company for its assistance and encouragement. Students were "selected" for participation in the study on the basis of pretest performances indicating they had the necessary precursor skills to be ready to learn the use of Cartesian coordinates but had not yet learned their use.
} 
changes in their performance on written pre- and posttest assessments of their knowledge of Cartesian coordinates. These measures, administered apart from the computer context several days before and several days after the experimental sessions, contained both questions asking for responses directly analogous to those asked of students by the target computer program and questions that required some further generalization of students' knowledge.

The results of this initial study seemed clear, although they revealed an unexpected difference in effects for boys vs. girls. On our primary measure of the motivational appeal of the activity, both boys and girls showed significant, and equally large, preferences for the motivationally embellished "game" version over the relatively unadorned "drill" version of the activity. Both groups chose the embellished version of the activity a much greater percentage of time than they did the unembellished version.

On all of our measures of learning, however, the results differed as a function of students' gender. For boys, the increased motivational appeal of the embellished activity was accompanied by greater learning as well. This was true for our measures of both direct learning and generalization of learning. These effects, moreover, did not seem to be a simple result of the increased time spent on the target program; when variance due to differences in time-on-task was partialed out, using an analysis of covariance, the differences in learning between the two groups remained significant. For girls, by contrast, there were no significant differences in learning, on either our measure of immediate learning or our measure of generalization of learning - despite the demonstrably increased motivational appeal, for them as well, of the embellished version of the activity. In fact, in both cases, the means for girls were nonsignificantly in the opposite direction. For boys, then, in this initial study, increased intrinsic motivation produced increased learning as well; for girls, increased intrinsic motivation produced no hint of any comparable positive effect.

Given these unanticipated gender differences, the obvious question is: Why? A second project, thus, sought to test one possible hypothesis that the particular fantasy context used in our initial study, that of hunting for buried pirate treasure, may have been somehow more compelling or relevant or familiar for boys than for girls. If so, then we should be able to design a fantasy context more suitable for girls and should then find the same beneficial effects of enhanced motivational appeal for girls as we had found in the first study for boys.

In conception, then, the design of our second experiment was quite straightforward: It involved a comparison of three versions of a target learning activity - one unembellished version of the activity and two embellished 
versions in which the same instruction, problems, and feedback were embedded in fantasies of demonstrable special appeal either to boys or to girls. Having both boys and girls working with each of these three alternative programs, then, yielded a $2 \times 3$ experimental design.

In most other respects, the procedures for our second project were derived from our first study, with a few additional improvements in design. Despite the results of the covariance analysis in our initial study, for example, one might still be concerned that the significant increases in learning obtained, for boys, in that study were simply the result of boys in the embellished activity condition having spent more time with the relevant educational activity. To eliminate this possibility in our second project, we tested the motivational appeal and the level of learning on different samples of students, allowing us to ensure that all students in "the learning study" spent identical amounts of time on task. Similarly, although the fantasy treasures displayed in the first study were intended simply as part of the general fantasy context, one might argue that their special status as "reinforcers" following correct responses was important. In the second study, therefore, we constrained our fantasy manipulation to remove such elements.

In this second study (Lepper \& Hodell, 1992), selected third- to fifthgraders were asked to work with one or another version of a different computer-based learning activity across four 20 -min sessions. ${ }^{4}$ Again, the experimental activity dealt with learning to use Cartesian coordinates, although using a rather different program. In this second study, in the basal, unembellished activity conditions, the program displayed a $10 \times 10$ matrix on which a visible white dot could be seen moving from one intersection of the grid to another. The goal of the activity was for the student, before time ran out, to surround this dot with colored squares, so that the dot could no longer move. The colored square barriers, of course, could only be placed to surround the dot by the student's indicating the coordinates where each square was to be placed.

In the two embellished activity conditions, naturally, this same activity was presented in one of two fantasy contexts designed to appeal especially either to boys or to girls. These fantasies, arrived at after fairly extensive interviewing of samples of boys and girls in the appropriate age

\footnotetext{
${ }^{4}$ The activities for this second session were once again produced from a commercial program developed by The Learning Company of Menlo Park, California. The program in this study was initially titled "Roadblock," and we are, once again, grateful to The Learning Company for providing us the source code for this program and its permission to use variants of this program in our study. Again, as in the first study, studenis were selected for participation on the basis of pretests establishing that they fell in the appropriate "window of opportunity" for learning from this program - i.e., that they possessed the requisite precursor skills, but were not already familiar with the material.
} 
range, involved the description of the activity in one case as armed hunters tracking down and surrounding a vicious mountain lion (the "masculine" version) or in the other case as adult mice surrounding an excited baby mouse to keep it from becoming lost (the "feminine" version). The instantiation of these different fantasy contexts, moreover, was relatively minimal. At the outset, when the program was first turned on, these programs showed a single different graphics page giving a different title and illustration to introduce the learning activity. Thus, the activity could be called either "Kill the Lion" or "Save Baby Mouse," with the different titles being accompanied by pictures of either a hunter carrying a shotgun or a baby mouse looking lost, respectively. The baseline control program, called "Stop the Dot," was accompanied by an abstract illustration on its title page.

Following these varying title pages that appeared before the students had even been informed of the nature of the activity, each of the activities remained absolutely identical - in problems, graphics, text, etc. - with one exception. On each trial, when the program asked the student to make a move or commented on the student's move, it described the squares and circle differentially as a function of the fantasy condition. Thus, these squares were referred to in the text as either hunters, mice, or merely squares; similarly, the dot would be referred to as the lion, the baby, or simply the dot.

With these three programs, a preliminary study was done with a first sample of boys and girls, to establish the differential motivational appeal of the activities created. These students were simply shown the different versions of the activity and were asked to indicate their preferences among them, in terms of a rank-ordering, and were then asked to choose one to work with during a single session. The results were clear: As expected, boys strongly preferred the "masculine" fantasy, whereas girls equally strongly preferred the "feminine" fantasy.

Given these results establishing the differential motivational appeal of the different versions of the activities, the stage was set for our main study on the learning that took place when students worked with them. For this purpose, a different sample of students was recruited, and each was asked to work with one of the experimental programs for a fixed amount of time. As in our initial study, changes in performance on a standard written test, administered outside the computer context a week before and again a week after the experimental sessions, served as our index of learning.

In light of the findings in our first study, of course, we expected to find that increases in learning would accompany increases in motivation when the fantasy employed was one suitable to the students. Hence, we 
expected increased learning for girls working with the feminine program and for boys working with the masculine program. Again, however, we were surprised by the actual results. Instead of the anticipated Gender $\times$ Condition interaction, the results tended to show gains in learning from all of the motivationally embellished programs, for both boys and girls, independent of the particular match between the students and the fantasy. ${ }^{5}$ Moreover, these effects were, if anything, stronger for girls than for boys. Both sexes, then, in this second experiment showed the beneficial effects of motivational embellishments on learning that only boys had shown in our initial study.

At the same time that this second study was underway, a third related study was also begun. This study also sought to address the unanticipated sex difference obtained in our first experiment, by offering a potential practical solution to the apparent problem of finding a suitable motivational strategy for different students. Suppose, we thought, we could offer all students an explicit choice among several different fantasy contexts in which a common learning activity might be embedded. If each student were allowed to select a fantasy that would be particularly compelling for him or her individually, then each student might show the learning benefits demonstrated for the boys in our initial study.

In a third study (Parker \& Lepper, 1992), therefore, we sought to create such a setting - one in which students could choose for themselves the learning context they preferred. In this third study, then, we created yet another set of alternative computer-based learning activities, this time involving children learning to work with a computer-graphics system, "turtle graphics," in the programming language Logo (Papert, 1980). For this study, three alternative fantasy contexts were created, into which a fourth basal or unembellished set of instructional activities could be embedded.

The four sets of computer-based instructional programs all involved a series of formally identical activities requiring the student to make use of basic graphics commands in Logo. These activities required children to learn how (a) to draw lines connecting various collections of objects on the screen, b) to negotiate a passage through a series of mazes displayed on the monitor, and (c) to construct a prescribed series of simple geometric shapes on the screen. In the basal, no-fantasy version of this activity, each of these activities involved simple "abstract" line drawings and geometric shapes, without any further embellishments.

\footnotetext{
${ }^{5}$ In fact, for both boys and girls, the means in this study would suggest that the gender-appropriate fantasy produced greater learning than the gender-inappropriate fantasy. With the small number of students we have per condition at this point, however, these predicted effects do not approach significance.
} 
The embellishments added in the fantasy versions were relatively subtle. The three fantasy versions of these activities involved an identical series of problems, but these problems were presented in the context of simple stories that embedded problem solutions in one of three fantasy contexts. In one case, the student was encouraged to think of himself or herself as a pirate in search of buried treasure. In another, the child was placed in the role of a detective hunting down criminals; in still another, the student was asked to pretend to be an astronaut seeking out new planets in space. These brief stories were accompanied by appropriate simple line drawings that supported the fantasy suggested.

For example, an initial activity in the no-fantasy lessons involved asking the students to draw lines connecting a circle at the center of the screen with a set of other circles displayed on the monitor. In a fantasy version of this activity, the circles on the screen would be presented as human faces and the student-astronauts would be asked to "go meet the other astronauts and bring them back to the ship" displayed in the center of the screen. Similarly, in a next activity in which students in the no-fantasy version were asked to connect a series of circles with a single line, student-astronauts would be asked to explore a series of planets. Parallel embellishments in the other cases featured stories and illustrations involving pirates or detectives.

As in our second study, we again wished to measure the motivational appeal and the instructional effects of our alternative programs independently, so that actual instructional time with the activity would not vary during our assessment of the effects of our manipulations on learning. Hence, we again conducted a preliminary study in which we demonstrated for students the different versions of our activities, and we asked them to rank-order these versions and to choose one to work with immediately afterward. As before, the results were clear and powerful. Both boys and girls showed a dramatic preference for the motivationally embellished versions over the unembellished version, although which specific embellished version was most preferred differed from student to student, with roughly equal numbers giving their top ranking to each of the three fantasy versions.

These findings, then, set the stage for our third study of learning. Three conditions were compared. In the control condition, third-grade students were asked to work with the unembellished program for a series of four 40-min sessions. In the two experimental conditions, other students were asked to work for a similar time with one of the motivationally embellished programs. In one experimental group, the students were each shown the three alternative fantasy programs and were asked to select the one they would like to work with during the study; in the other experimental 
group, the students were assigned to work with specific fantasies yoked to the choices of those in the other group. Written tests of students' mastery of the Logo language itself and of their more general understanding of the geometric concepts underlying graphics programming in Logo served as the dependent measures in this study. The direct learning measure was administered only after students had finished the study (since none of them had had prior exposure to this language beforehand); the generalization measure was administered both before and again after the experimental sessions. Both tests were also given a final time 2 weeks after the sessions had been completed.

The results were once again straightforward. Compared to students who learned from the unembellished control program, students who learned from an embellished fantasy program showed greater learning. This was true for both boys and girls, it was true for both the immediate and the delayed posttests, and it was true whether the students had been allowed to choose for themselves the fantasy version of the program they most preferred or they had been assigned a fantasy version arbitrarily. For the more distal generalization measure, comparable results were apparent, although the superiority of the fantasy conditions was statistically significant only for the delayed test administration.

In each of these three studies of computer-based learning, then, the addition of relatively minor motivational embellishments providing a fantasy context in which problems were to be solved proved successful, for both boys and girls, in producing heightened interest in the learning activity. In five of the six relevant comparisons, examining the results separately for boys and for girls, this heightened motivational appeal also produced corresponding increases in learning. ${ }^{6}$

${ }^{6}$ It would, of course, be nice to have a determinate explanation for the divergent results obtained for girls in the first study. Given the unanticipated parallel results for girls and boys in our later studies, we do not have a good explanation of this sort. Perhaps subsequent studies will help us to understand these conflicting findings further, or perhaps it is simply a probabilistic phenomenon - that the effect is, indeed, weaker for girls and will more often prove nonsignificant in any particular study. In line with this latter possibility, it is worth noting that a similar pattern of findings characterizes the correlational work of Asher and his colleagues on the role of topic interest in reading comprehension, which was mentioned earlier. In fact, in one of Asher's studies (e.g., Asher \& Markell, 1974) an unexpected gender difference, exactly paralleling the results of our first study, was apparent: Specifically, rated interest value of the text proved highly correlated with comprehension for boys, but was much less strongly correlated with comprehension for girls. In other of his studies (e.g., Asher, 1979, 1980; Asher, et al., 1978), by contrast, no gender differences were obtained, and significant positive correlations between interest value and text comprehension were obtained for both boys and girls. 
Finally, in addition across these studies, data were collected to speak to the question of the effects of such procedures on students' subsequent interest in the subject matter itself - to ask whether positive attitudes toward the activity will later generalize to the classroom, even when the motivational embellishments are no longer present, or whether the removal of those previous motivational elements will make later unadorned presentations of the subject matter itself seem boring and uninviting. Thus, in each of the studies, students were asked, both before and after the experimental sessions, to indicate how much they liked, and felt competent in, math and school more generally. In the first two studies, where such a measure was possible, students were also subsequently asked by their classroom teachers how much they would like to work in class, outside the computer context, on the types of math problems they had worked at the computer.

The results from these measures of subsequent motivation can be summarized with two statements: First, on most of these measures there were no significant differences among conditions; usually subsequent interest was rated extremely high by all groups. Second, however, whenever there was a significant difference between groups, it showed a significant positive effect of motivational embellishments on later motivation. In particular, in the first study, no significant differences were obtained. In the second study, students in the motivational embellishment conditions indicated to their classroom teachers a greater level of interest in continuing to work on the sorts of graphing problems featured in the experimental activity than students in the nonembellished conditions. Finally, in the third study, students in the embellishment conditions showed a marginally significant increase in their positive attitudes toward math and towards school, compared to their counterparts in the nonembellishment conditions.

The positive effects shown in these studies - on immediate interest, on learning and generalization of learning, and occasionally on subsequent motivation - of adding further intrinsic rewards to a learning activity obviously contrast sharply with the detrimental effects that adding extrinsic rewards have been shown to have on learning and motivation. Clearly, however, there are many, many ways in which the paradigms and procedures employed in these two different lines of investigation differ. As a result, in the final study to be reported here, we sought to contrast directly the effects of these two different strategies for enhancing momentary motivation and, at the same time, to begin to study more directly the effects of these two types of motivational strategies on the process of learning. 
In this last study, then, we compared the ways in which the addition of further intrinsic vs. extrinsic rewards may influence the actual process of learning and problem solving (Cordova \& Lepper, 1992). In this study, fourth- and fifth-grade students participated in two experimental sessions involving concept-learning activities patterned after Bruner, Goodnow, and Austin (1956) and Condry and Chambers (1978), from which we could examine the step-by-step process of learning and assess the effectiveness of children's problem-solving strategies.

Thus, in a first experimental session, students were asked to engage in a moderately complex concept-attainment task similar to that posed in the popular boardgame Clue. Specifically, the children were told that their job consisted of determining a randomly selected particular combination of "facts" regarding a hypothetical "crime." In order to figure out this randomly chosen combination, the children were instructed to select from three stacks of cards which had been placed directly in front of them a set which reflected their "hunch." The first, blue set of cards contained the names of three suspects. The second, pink set contained the names of three tools which the burglar might have utilized in order to open the vault from which the money had been stolen. The third, yellow stack contained the names of three possible locations where the money could have been hidden by the burglar. Indicating a given hunch, thus, constituted one trial at the task.

After the students had stated a hypothesis, the experimenter provided them with feedback regarding their particular choice of cards. More specifically, the child was told whether the stated combination of "facts" was "completely wrong," "partially right," or "completely right." At this point, the student was exhorted to formulate and test another hypothesis regarding the fictitious crime. This process continued until the student had arrived at the targeted combination of facts. Subsequently, all subjects were administered a short questionnaire assessing their feelings of self-efficacy and interest toward the task.

Our research design - a $2 \times 2$ factorial - featured the presence or absence of an extrinsic reward (in this study, the chance to choose a toy from the experimenter's "mystery box") and the presence or absence of an added intrinsic reward (in the form of an interesting fantasy context in which problem solving could be embedded). Specifically, subjects in the fantasy-present conditions read a brief, yet highly engaging, comic-bookstyle prologue that described the robbery and invited the children to play the role of "detectives" faced with the challenge of figuring out exactly how the robbery had been committed. Children's successive hunches were, of course, recorded, permitting the later derivation and analysis of a variety of measures of the efficiency of students' strategies. 
Across many measures of problem-solving effectiveness, we found that the presence of a fantasy context led children to use more efficient and more elaborate problem-solving strategies and to achieve extremely high levels of performance. Compared to our baseline condition, for example, students in this motivational embellishment condition required significantly fewer trials to arrive at the target combination of facts and formulated hypotheses in a demonstrably more systematic and informative manner, offering, for instance, only one-fifth as many redundant hypotheses as those subjects in the unembellished condition. Moreover, these students saw themselves as more capable at the task, and they selectively chose to attempt more difficult problems at a later time.

By contrast, on these same measures, we found that the offer of an extrinsic reward for finding the correct answer had dramatic negative effects on students' problem solving. Students anticipating the receipt of an extrinsic reward for a correct solution took many more trials to arrive at that correct solution, formulated hypotheses in a much less systematic fashion, and saw themselves later as less competent at the task. Even when students were also presented with the intrinsic reward that otherwise enhanced performance, the performance of students expecting an extrinsic reward remained exceedingly low.

One week later, all of these same students participated in a second session in which they were presented with a related, but more abstract, concept-attainment task in the absence of both types of motivational embellishments. Impressively, many of the effects obtained in the first session persisted and generalized to this new task. For instance, relative to controls, students who had previously been in the intrinsic reward condition continued to require significantly fewer trials to arrive at the target concept, offered significantly fewer redundant hypotheses, and continued to express a preference for more challenging problems in the future. Conversely, students who had previously been offered extrinsic rewards for success took much longer to solve the problem, continued to require more trials in order to arrive at the targeted concept, offered approximately 10 times as many illogical hypotheses, perceived themselves as being much worse at the task and continued to express a preference for less challenging problems in the future, relative to subjects who had not been offered an extrinsic incentive for task engagement in the first session.

\section{THEORETICAL CONSIDERATIONS}

The empirical investigations recounted here thus suggest that, when appropriately designed, relatively small intrinsic motivational embellishments can have substantial educational benefits of several sorts - positive 
effects that stand in contrast to the substantial detrimental educational effects that the provision of tangible extrinsic rewards frequently produces. Under the best of circumstances, these benefits can include increased learning and retention of the material, greater generalization of that learning, heightened subsequent interest in the subject matter, enhanced confidence in the learner, and improvements in the actual process of learning. As Locke suggested long ago, there are significant gains to be had when learning is viewed by students as play, and significant costs to be paid when learning is seen instead as work.

That being said, it is important to be clear that our argument is simultaneously both much broader, and considerably more limited, than the foregoing studies might suggest. On the one hand, we wish to argue that there are a number of techniques for enhancing the intrinsic motivational appeal of educational activities, even though we have focused experimentally on only one basic motivational embellishment strategy. On the other hand, we also wish to argue that motivational embellishments will not automatically, or even typically, produce the positive educational outcomes seen in our experiments; instead, the instructional effects of motivational embellishments in general may vary dramatically as a function of the specific manner in which they are incorporated into particular educational activities.

Consider, first, the broader argument. In the studies reported here, we employed a fairly natrow range of strategies for increasing the intrinsic motivational appeal of our activities. We did so because we wished, in these studies, simultaneously to control the cognitive structure of the activity while varying its motivational appeal, and we found it difficult to do so with many of the more obvious strategies one might use to increase students' motivation at an activity.

In an extended conceptual analysis of the determinants of intrinsic motivations for learning, for instance, Malone and Lepper (1987) identified four basic sources of intrinsic motivation - challenge, curiosity, control, and fantasy - each of which might be targeted for enhancement. Manipulations that would effectively increase any of these sources of interest might then be expected to have potential benefits for learning. Many of these factors, however, would be difficult to vary, without simultaneously varying obvious cognitive parameters known to influence learning. Varying the degree of challenge posed by an activity for a learner, for example, could be accomplished by varying the difficulty of the problems presented to the learner or the amount of help the learner is provided. Were increases in learning as a function of increases in motivational appeal observed in either of the cases, however, it would be difficult to determine the appropriate interpretation of such effects. 
Consider, for example, the studies by Ross and his associates on the "personalization" of learning (Ross, 1983; Anand \& Ross, 1987; Ross, McCormick, \& Krisak, 1986). In these studies, students are presented with instructional materials and problems either in a purely abstract form, or in one of several more concrete forms designed to involve contexts and/or actors either related or unrelated to the student's previously expressed interests. In these studies, "personalization" of instructional materials appears to have substantial beneficial effects on initial learning, the transfer of learning to new abstract problems, and a variety of motivational measures.

In one recent study (Anand \& Ross, 1987), for example, fifth- and sixth-grade students studied one of three versions of a computer-assisted lesson on division of fractions. In one version of the activity, examples were personalized by incorporating specific information about the individual student (i.e., his or her favorite teacher, friend, or food) into the problem contexts. In a second version, a more "generic," but equally concrete context was used, which involved specific but hypothetical referents such as Mrs. Smith, your friend, candy bar, in order to convey an integrated and realistic application. By contrast, a third version involved the use of purely abstract concepts and general referents, such as quantity, liquid, and so forth, without any association whatsoever to a meaningful background theme. In general, the results favored the personalized-context group over the other groups in terms of their success in solving both standard and transfer problems, their recognition of rule procedures, and their motivation, as indexed by a series of measures designed to assess the students' attitudes toward the task.

Such findings, of course, are entirely consistent with the analysis proposed in this paper. It is also possible to construct a more purely cognitive analysis of these effects, in terms of the meaningfulness of the material to be learned, as well. Nevertheless, such findings do suggest the potentially wider applicability of the arguments being offered here.

Let us turn, then, to some of the limitations of these arguments. Throughout this paper, we have tried to stress that our experiments were explicitly undertaken in order to see whether significant educational benefits could be found from the use of simple motivational embellishments. As a result, in these studies, we sought to design our activities deliberately so as to maximize the likelihood of observing positive effects of our motivational manipulations.

From such findings, therefore, it would be an unwarranted extrapolation to suggest that the use of motivational embellishment strategies will always, or even typically, have such beneficial effects. Indeed, there is every reason to believe that they will not. Lepper and Malone (1987), for example, 
explicitly identify a number of situations in which increases in the motivational appeal of specific computer-based learning activities failed to produce corresponding increases in learning, or other desired educational outcomes.

The most general principle determining whether increased motivational appeal will lead to increased learning, Lepper and Malone (1987) suggested, concerns the "match" between the actions required for students to learn the material being presented in an activity and the actions required for students to enjoy that activity. When these actions are identical or mutually reinforcing, the effects on learning should be positive; when these actions are mutually exclusive or otherwise at variance with one another, the effects on learning should be negative.

In the specific case of instructional games, for example, we may examine the relationship, as noted earlier, between the goals of winning the game and learning the material (Lepper \& Malone, 1987). In the best of these activities, these two sets of goals are congruent and mutually supportive; under such conditions, as in the studies discussed earlier, the added motivational value of presenting instruction in a game format should produce increased learning. In other such activities, these two sets of goals are simply independent of one another; here the consequences on learning should depend simply on the extent to which motivational activities take up time that would otherwise have been devoted to learning. In the worst cases, however, these two sets of goals are directly at odds with one another; in such cases, learning will suffer from the addition of motivational embellishments of this sort. Lepper and Malone (1987) describe a number of common computer-based educational activities at which student motivation has been clearly enhanced, but with detrimental consequences for student learning.

These basic principles may apply at many different levels of abstraction within a learning activity. The addition of illustrations, or exciting anecdotes, to a text may enhance learning if they draw the learner's attention to the salient characters and actions in a story or to important themes and arguments in an informational passage. They may have detrimental effects on learning, however, if they draw the student's attention toward minor, incidental, or irrelevant aspects of the passage.

One specific example of such a mismatch that has been studied at length concerns the effects of adding "seductive details" to passages to be learned (Garner, Alexander, Gillingham, Kulikowich, \& Brown, 1991; Hidi, 1990; Garner, Gillingham, \& White, 1989). For instance, in a recent study by Garner et al. (1989), both children and adults were asked to read a three-paragraph expository text on the topic of differences among insects. Each proposition in the text had been previously rated for importance and 
for interest by a panel of experts. For example, raters found generalizations about insect differences to be very important, but quite uninteresting. On the other hand, they had found details about clicking beetles, buzzing flies, and ravenous snakes to be very interesting, but not even moderately important. At each age level, half of the readers read the entire text with interesting yet unimportant details, and the remaining half read it without the inclusion of these "seductive" propositions. In general, the recall of important information in the text differed dramatically by condition for both children and adults: Whereas subjects who read the text without the interesting details recalled an average of $93 \%$ of the ideas rated by judges as most important in the text, subjects provided with provocative details recalled an average of only $43 \%$ of those key ideas.

In short, we believe that there are significant educational benefits to be gained from more effective attempts to heighten children's intrinsic interest in the instructional activities they are presented. These positive effects, however, will not occur automatically; we must plan our use of motivational embellishments carefully, to ensure that they support, rather than undermine, learning. The potential payoff, however, is considerable. For years, schools have unwittingly turned the play of learning into work; it seems high time that we returned to Locke's suggestion that we seek instead to make work into play - so that more students might indeed be brought to a desire to be taught.

\section{REFERENCES}

Amabile, T. M. (1979). Effects of external evaluation on artistic creativity. Journal of Personality and Social Psychology, 37, 221-233.

Amabile, T. M. (1983). The social psychology of creativity. New York: Springer-Verlag.

Anand, P., \& Ross, S. M. (1987). A computer-based strategy for personalizing verbal problems in teaching mathematics. Educational Communication and Technology Journal, 35, 151-162.

Anderson, R. C. (1982). Allocation of attention during reading. In A. Flammer \& W. Kintsch (Eds.), Discourse processing (pp. 287-299). Amsterdam: North Holland.

Anderson, R. C., Mason, J., \& Shirey, L. (1984). The reading group: An experimental investigation of a labyrinth. Reading Research Quarterly, 20, 6-36.

Anderson, R. C., Shirey, L. L., Wilson, P. T., \& Fielding, L. G. (1987). Interestingness of children's reading material. In R. E. Snow \& M. C. Farr (Eds.), Aptitude, learning, and instruction: III. Conative and affective process analyses (pp. 287-299). Hillsdale, NJ: Erlbaum.

Asher, S. R. (1979). Influence of topic interest on black children's and white children's reading comprehension. Child Development, 50, 686-690.

Asher, S. R. (1980). Topic interest and children's reading comprehension. In R. J. Spiro, B. C. Bruce, \& W. F. Brewer (Eds.), Theoretical issues in reading comprehension (pp. 525-534). Hillsdale, NJ: Erlbaum.

Asher, S. R., Hymel, S., \& Wigfield, A. (1978). Influence of topic interest on children's reading comprehension. Joumal of Reading Behavior, 10, 35-47. 
Asher, S. R., \& Markell, R. A. (1974). Sex differences in comprehension of high- and low-interest reading material. Journal of Educational Psychology, 66, 680-687.

Bruner, J., Goodnow, J., \& Austin, G. (1956). A study of thinking. New York: Wiley.

Condry, J. (1977). Enemies of exploration: Self-initiated versus other-initiated learning. Journal of Personality and Social Psychology, 35, 459-475.

Condry, J., \& Chambers, J. (1978). Intrinsic motivation and the process of learning. In $\mathbf{M}$. R. Lepper \& D. Greene (Eds.), The hidden costs of reward (pp. 61-84). Hillsdale, NJ: Erlbaum.

Cordova, D. 1., \& Lepper, M. R. (1992). The effects of intrinsic versus extrinsic rewards on the learning process. Unpublished manuscript, Stanford University.

D'Altore, A. (1981). Computer-aided instruction, boon or bust? Computel, 12, 18-20.

Deci, E. L. (1975). Intrinsic motivation. New York: Plenum Press.

Deci, E. L., \& Ryan, R. M. (1985). Intrinsic motivation and self-determination in human behavior. New York: Plenum Press.

Garner, R., Alexander, P. A., Gillingham, M. G., Kulikowich, J. M., \& Brown, R. (1991). Interest and learning from text. American Educational Research Joumal, 28, 643-659.

Garner, R., Gillingham, M. G., \& White, C. S. (1989). Effects of "seductive details" on macroprocessing and microprocessing in adults and children. Cognition and Instruction, 6, 41-57.

Glucksberg, $S$. (1962). The influence of strength of drive on functional fixedness and perceptual recognition. Joumal of Experimental Psychology, 63, 36-41.

Glucksberg, S. (1964). Problem solving: Response competition and the influence of drive. Psychological Reports, 15, 939-942.

Hidi, S. (1990). Interest and its contribution as a mental resource for learning. Review of Educational Research, 60, 549-571.

Kleiman, G. M. (1984), Brave new schools: How computers can change education: Reston, VA: Reston.

Lepper, M. R. (1981). Intrinsic and extrinsic motivation in children: Detrimental effects of superfluous social controls. In W. A. Collins (Ed.), Minnesota symposium on child psychology (Vol. 14, pp. 155-214). Hillsdale, N. J.: Erlbaum.

Lepper, M. R. (1983). Social control processes and the internalization of social values: An attributional perspective. In E. T. Higgins, D. N. Ruble, \& W. W. Hartup (Eds.), Developmental social cognition: $A$ sociocultural perspective (pp. 294-330). New York: Cambridge University Press.

Lepper, M. R. (1985). Microcomputers in education: Motivational and social issues. American Psychologist, 40, 1-18.

Lepper, M. R. (1988). Motivational considerations in the study of instruction. Cognition and Insiruction, 5, 289-309.

Lepper, M. R., \& Gilovich, T. (1981). The multiple functions of reward: A social-developmental perspective. In S. S. Brehm, S. M. Kassin, \& F. X. Gibbons (Eds.), Developmental social psychology (pp. 5-31). New York: Oxford University Press.

Lepper, M. R., \& Greene, D. (1978). Overjustification research and beyond: Toward a means-ends analysis of intrinsic and extrinsic motivation. In M. R. Lepper \& D. Greene (Eds.), The hidden costs of reward (pp. 109-148). Hillsdale, N.J.: Erlbaum.

Lepper, M. R., \& Hodell, M. (1989). Intrinsic motivation in the classroom. In C. Ames \& R. Ames (Eds.), Research on motivation in education (Vol. 3, pp. 73-105). New York: Academic Press.

Lepper, M. R., \& Hodell, M. (1992). Instructional games: Effects of sex-typed fantasy contexts on boys' and girls' learning and instruction. Unpublished manuscript, Stanford University.

Lepper, M. R., \& Malone, T. W. (1987). Intrinsic motivation and instructional effectiveness in computer-based education. In R. E. Snow \& M. J. Farr (Eds.), Aptitude, learning, and instruction: III. Conative and affective process analyses (pp. 255-296). Hillsdale, N. J.: Erlbaum.

Locke, J. (1963). Some thoughts concerning education. London: A. \& J. Churchill.

Malone, T. W., \& Lepper, M. R. (1987). Making learning fun: A taxonomy of intrinsic motivations for learning. In R. E. Snow \& M. J. Farr (Eds.), Aptitude, learning, and 
instruction: III. Conative and affective process analyses (pp. 223-253). Hillsdale, NJ: Erlbaum.

McGraw, K. O. (1978). The detrimental effects of reward on performance: A literature review and a prediction model. In M. R. Lepper \& D. Greene (Eds.), The hidden costs of reward (pp. 33-60). Hillsdale, NJ: Erlbaum.

McGraw, K. O., \& McCullers, J. C. (1979). Evidence of a detrimental effect of extrinsic incentives on breaking a mental set. Journal of Experimental Social Psychology, 15, 285-294.

Papert, S. (1980). Mindstorms: Children, computers, and powerful ideas. New York: Basic Books.

Parker, L. E., \& Lepper, M. R. (1992). The effects of fantasy contexts on children's learning and motivation: Making learning more fun. Journal of Personality and Social Psychology, $62,625-633$.

Psotka, J. (1982). Computers and education, Behavior Research Methods and Instrumentation, 14, 221-223.

Ross, S. M. (1983). Increasing the meaningfulness of quantitative material by adapting context to student background. Journal of Educational Psychology, 75, 519-529,

Ross, S. M., McCormick, D., \& Krisak, N. (1986). Adapting the thematic context of mathematical problems to student interests: Individual versus group-based strategies. Journal of Educational Research, 79, 245-252.

Thornburg, D. D. (1981). Computers and society: Some speculations on the well-played game. Compute!, 14, 12-16. 